Bangladesh J. Bot. 42(1): 51-53, 2013 (June)

\title{
CHEMICAL INVESTIGATION OF CORYPHA TALIERA ROXB.
}

\author{
Mohammad Shoeb*, Shefat-E-NusRat And Moniruzzaman KhondKer ${ }^{1}$ \\ Department of Chemistry, University of Dhaka, Dhaka-1000, Bangladesh
}

Key words: Corypha taliera, $\beta$-sitosterol, Fatty acid, Palmitic acid, Linoleic acid, Chromatography

\begin{abstract}
$\beta$-sitosterol was isolated by silica gel column chromatography from the dichloromethane soluble extract of pericarp of Corypha taliera Roxb. (Talipalm), a rare species of Arecaceae family. The compound was characterized by IR, ${ }^{1} \mathrm{H}$ and ${ }^{13} \mathrm{C}$ NMR spectroscopic studies. Fatty acid compositions of oil of the pericarp was determined as their methyl esters and identified by gas chromatography having flame ionization and the gas chromatograph was coupled to mass spectroscopic detectors. Myristic, palmitic, oleic, linoleic, stearic, arachidic and lignoceric acids were found to be present in the oil. The palmitic acid was predominant $(50.75 \%)$ in the oil. The relative percentage of unsaturated acid i.e., linoleic and oleic acids was found to be
\end{abstract} 15.58 and $20.89 \%$, respectively.

\section{Introduction}

Corypha taliera Roxb. belongs to the family Arecaceae. William Roxburgh discovered the plant in 1819 and reported it to be endemic to Bengal (Roxburgh 1820, Roxburgh 1832, Basu 1991). There are four species of the genus Corypha, namely Corypha taliera, C. umbraculifera, C. elata and C. macropoda available in the Indian subcontinent. C. taliera locally known as Talipalm, is a globally endangered species (Khondker et al. 2010). The existence of C. taliera in Bangladesh was identified by late Prof. Salar Khan in 1950 in the Dhaka University Campus, Dhaka (Khondker et al. 2010). This palm grows for ca. 80 years without producing flower. There is no information on the phytochemical work with this plant. However, literature survey showed that flavonoid, flavonoid glycosides, phenolics and carotenoids are present in plants of Arecaceae family (Kang et al. 2010). Some species of Corypha are also traditionally used for bowel complaints, diarrhoea and cough (Gunasekaran and Balasubramanian 2012). Palm trees are also well-known as one of the sources of vegetable oil. In the present study, we report for the first time the fatty acid composition of the oil and isolation of $\beta$-sitosterol from $C$. taliera.

\section{Materials and Methods}

Instruments: IR spectrum was recorded on Shimadzu IR-470 spectrometer. The ${ }^{1} \mathrm{H}$ and ${ }^{13} \mathrm{C}$ NMR spectra were recorded on a Bruker $400 \mathrm{MHz}$ spectrometer using tetramethylsilane (TMS) as the internal reference. Gas chromatographic (GC) analyses were performed on a Shimadzu 2025 GC connected with a flame ionization detector (FID). Nitrogen and hydrogen and air were used as carrier gas and flame, respectively. Separations were performed on HP-5 capillary WCOT quartz columns (30 m long and 0.25 inner diameter; film thickness was $0.25 \mu \mathrm{m}$ ). Column flow rate was $2 \mathrm{ml} / \mathrm{min}$ and split ratio was $1: 79$. The column oven temperature was programmed for analysis: $120^{\circ} \mathrm{C}(1 \mathrm{~min}$ hold time $)$ to $270^{\circ} \mathrm{C}(6 \mathrm{~min})$ and $7^{\circ} \mathrm{C}$ rise per min. Injector and detector temperature were set 280 and $290^{\circ} \mathrm{C}$, respectively. Gas chromatographic and mass spectrometric analyses were carried out on an Agilent Mass Spectrometer (Model No. 6890 N) coupled with a Gas Chromatograph (Model No. 5975 B). Separations were performed on a HP-5 MS 5\% phenyl methyl siloxane column ( $30 \mathrm{~m}$, i.d.: $0.25 \mathrm{~mm}$, film thickness: 0.25 microns $)$ at temperature $120^{\circ} \mathrm{C}$

*Author for correspondence: <shoeb71@yahoo.com>. ${ }^{1}$ Department of Botany, University of Dhaka, Dhaka-1000, Bangladesh. 
$(1 \mathrm{~min})$ in a rate $7^{\circ} \mathrm{C}$ rise $\mathrm{min}$ to $270^{\circ} \mathrm{C}(6 \mathrm{~min})$. Injector temperature was fixed at $280^{\circ} \mathrm{C}$ and compounds were detected in scan the mode.

Collection of plant material: The fruits of C. taliera were collected from the lone individual existed in the campus of the University of Dhaka (Khondker et al. 2010). The pericarp were separated from the seeds of dried fruits and made into powder.

Extraction: Pericarp powder $(25 \mathrm{~g})$ was successively extracted with $n$-hexane $(100 \mathrm{ml} \times 3 ; 24$ h), dichloromethane (DCM, $100 \mathrm{ml} \times 3 ; 24 \mathrm{hr})$ and methanol $(\mathrm{MeOH}, 100 \mathrm{ml} \times 3)$. The extracts were collected by suction filtration from the residual pericarp and were evaporated to dryness by rotary vacuum evaporator followed by a freeze-dryer. Thus, $n$-hexane $(2.0 \mathrm{~g})$, DCM $(2.5 \mathrm{~g})$ and $\mathrm{MeOH}(2.0 \mathrm{~g})$ extracts were obtained. The present studies were done with $n$-hexane and dichloromethane extracts.

Isolation of compound: The DCM extract was fractionated by silica gel column chromatography. A glass column was made with the slurry of silica gel $60(0.063-0.200 \mathrm{~mm})$ and the column was equilibrated with $n$-hexane. The DCM extract was passed through the column and the column was eluted with 0 to $100 \%$ DCM in hexane followed by 2 to $10 \% \mathrm{MeOH}$ in DCM and finally eluted with $50 \% \mathrm{MeOH}$ in DCM. All fractions were collected in conical flasks and monitored by TLC. On the basis of the pattern of TLC, eight fractions were made. The fraction obtained from $100 \%$ DCM gave a single spot on TLC and was purified by washing with $n$-hexane several times to get compound $\mathbf{1}(10 \mathrm{mg})$ as white needles.

Properties of compound 1: White needles (10 mg), $\mathrm{R}_{\mathrm{f}}$ value 0.80 (100\% DCM ), FT-IR ( $\mathrm{KBr}$ pellets): $v_{\max } 3432,2928,2858,1639,1055 \mathrm{~cm}^{-1}$.

${ }^{1} \mathrm{H}$ NMR $\left(\mathrm{CDCl}_{3}\right): \delta 5.34(\mathrm{~s}, 1 \mathrm{H}), 3.51(\mathrm{~m}, 1 \mathrm{H}), 2.27(\mathrm{~m}, 2 \mathrm{H}), 1.99(\mathrm{~m}, 2 \mathrm{H}), 1.48,1.24(\mathrm{~m})$, $1.00(\mathrm{~s}, 3 \mathrm{H}), 1.82(\mathrm{~m}, 2 \mathrm{H}), 0.67(\mathrm{~s}, 3 \mathrm{H}), 0.85(\mathrm{t}, \mathrm{J}=7.2 \mathrm{~Hz}, 3 \mathrm{H}), 0.84,0.82,0.92$ (each d, J=6.4 Hz, $3 \mathrm{H} \times 3)$.

${ }^{13} \mathrm{C}$ NMR $\left(\mathrm{CDCl}_{3}\right): \delta 140.8,121.7,71.9,56.8,56.1,50.2,45.9,42.6,43.3,39.8,37.3,36.5$, 36.2, 34.0, 31.9, 31.8, 31.7, 29.2, 28.3, 26.2, 24.3, 23.1, 21.1, 19.8, 19.4,19.1, 18.8, 12.0, 11.9.

Analysis for fatty acid composition: Hexane extract $(100 \mathrm{mg})$ was saponified with $1.0 \mathrm{ml}$ of $0.5 \mathrm{M}$ methanolic $\mathrm{NaOH}$ solution in a boiling water bath at about $96^{\circ} \mathrm{C}$ for 3 hours and evaporated to dryness. The dried material was dissolved in water $(\sim 1.0 \mathrm{ml})$ acidified with a few drops $2 \mathrm{M}$ $\mathrm{HCl}$ and partitioned with $n$-Hexane. The hexane extract (free fatty acids) was evaporated to dryness under blowing nitrogen. Borontrifluoride-methanol $\left(\mathrm{BF}_{3}-\mathrm{MeOH}, 1 \mathrm{ml}\right)$ complex was added to the dried free fatty acids, ultrasonicated (votexed $30 \mathrm{sec}$.), heated in a boiling water bath for $30 \mathrm{~min}$ and evaporated into dryness. $n$-hexane $(\sim 1 \mathrm{ml})$ was added to the dried methyl esters, filtered through Pasteur pipette containing cotton, transferred to a GC-MS vial and analyzed by GC-FID and GC-MS. Certified methyl ester of fatty acids purchased from Sigma-Aldrich were used as reference samples for GC-FID.

\section{Results and Discussion}

Silica gel column chromatography of the DCM extract of $C$. taliera afforded a pure compound (1). The ${ }^{1} \mathrm{H}$ NMR spectrum of 1 gave signals at $\delta 5.34(\mathrm{~s}, 1 \mathrm{H}), 3.51(\mathrm{~m}, 1 \mathrm{H})$ which were characteristics of a steroidal nucleus (Greca et al. 1990). The signals at $1.00(\mathrm{~s}, 3 \mathrm{H}), 0.92(\mathrm{~d}, 6.4$ $\mathrm{Hz}, 3 \mathrm{H}), 0.85(\mathrm{t}, 7.2 \mathrm{~Hz}, 3 \mathrm{H}), 0.84,0.82($ each $\mathrm{d}, 6.4 \mathrm{~Hz}, 3 \mathrm{H} \times 2)$ and $0.67(\mathrm{~s}, 3 \mathrm{H}) \mathrm{ppm}$ in the ${ }^{1} \mathrm{H}$ NMR spectrum indicated the presence of 6-methyl groups. The signals at $2.24-1.48 \mathrm{ppm}$ were for the presence of methylene groups. The ${ }^{13} \mathrm{C}$ NMR spectral data revealed the presence of 29 carbon atoms; two quaternary carbons ( $\delta \mathrm{c} 42.6$ and $36.5 \mathrm{ppm}$ ), two olefinic ( $\delta \mathrm{c} 140.8$ and 121.7 $\mathrm{ppm})$ including a quaternary carbon, eight methine $(\delta \mathrm{c} 71.9,56.8,56.1,50.2,45.9,36.2,31.9$ and $29.2 \mathrm{ppm}), 11$ methylene ( $\delta \mathrm{c} 42.3,39.8,37.3,34.0,31.9,31.7,28.3,26.2,24.3,21.1$ and 23.1 
ppm) and six methyl groups ( $\delta \mathrm{c} 19.8,19.4,19.1,18.8,12.0$ and $11.9 \mathrm{ppm})$ were present. The signal at $\delta \mathrm{c} 71.9$ was due to the attachment of a hydroxyl $(-\mathrm{OH})$ group. ${ }^{1} \mathrm{H}$ and ${ }^{13} \mathrm{C}$ NMR spectral data of 1 were compared with reported NMR data of steroidal compounds (Greca et al. 1990) and were found to be consistent with $\beta$-sitosterol. Thus, $\mathbf{1}$ was confirmed as $\beta$-sitosterol. The isolation of $\beta$-sitosterol from $C$. taliera is reported here for the first time.

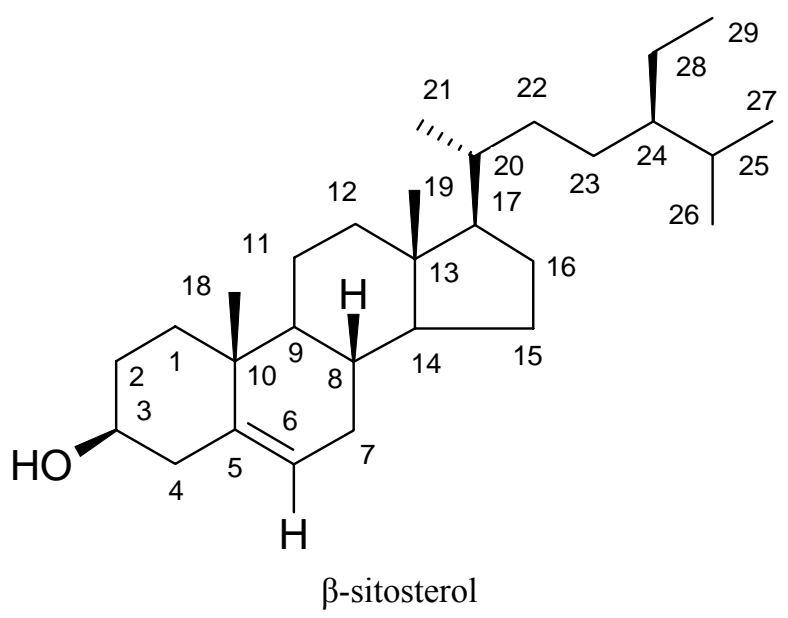

The fatty acids in hexane extract were made into their methyl ester by saponification with methanolic $\mathrm{NaOH}$ followed by esterification with $\mathrm{BF}_{3}-\mathrm{MeOH}$ complex, and analyzed by GC-FID. The relative percentage of methyl ester of fatty acids in oil was identified by comparing their retention time with that of methyl ester of standard fatty acids. It was found that myristic, palmitic, oleic, linoleic, stearic, arachidic and lignoceric acid were found in the hexane extract of pericarp of C. taliera. All fatty acids were confirmed by GC-MS. The methyl ester of palmitic acid gave $\mathrm{m} / \mathrm{z}$ at 270 while linoleic acid had $\mathrm{m} / \mathrm{z}$ at 295 . The palmitic acid was predominant $(50.75 \%)$ in the oil. The relative percentage of unsaturated acid i,e., linoleic acid and oleic acid were found to be 15.58 and $20.89 \%$, respectively. Unsaturated fatty acids are good for health. If C. taliera is propagated in a large scale, there is a good possibility to get oil from the seeds of the plant which is rich in unsaturated fatty acids.

\section{References}

Basu SK 1991. Palm utilization and conservation in India, Indonesia, Malaysia and the Philippines. In: Johnson D (ed), Palms for Human needs in Asia. pp. 27-28.

Greca MD, Monaco P and Previtera L 1990. Stigmasterol from Typha latipolia. Journal of Natural Products. 53 (6): 1430-1435.

Gunasekaran M and Balasubramanian P 2012. Ethnobotany Research and Application. 10: 253-268.

Kang J, Li Z, Wu T, Jensen GS, Schauss AG and Wu X 2010, Antioxidant capacities of flavonoid compounds isolated from acai pulp (Euterpe oleracea Mart). Food Chemistry 122: 610-617.

Khondker M, Hassan MA, Alfasane MA and Shahjadee UF 2010. Flowering and fruiting characteristics and biochemical composition of an endangered Palm species (Corypha taliera Roxb.). Bangladesh J. Plant Taxon. 17(1): 79-86.

Roxburgh W 1820. Flora Indica. Serampore 3: 51, t. 255-256.

Roxburgh W 1832. Flora Indica (Ed. 2). Serampore. 